\section{FROM MARIJUANA TO INTERNET AND VIDEO GAMING ADICTION- A CASE REPORT}

Received 30 August 2021;

Received in revised form 18 September 2021 Accepted 21 September 2021

\section{Lavinia-Alexandra Moroianu ${ }^{1,2}$ (1), Marius Moroianu ${ }^{3,4 凶, ~ A n a m a r i a ~ C i u b a r a ̆ ~}{ }^{1,2}$}

\author{
${ }^{1}$ Hospital of Psychiatry "Elisabeta Doamna", Galați; \\ ${ }^{2}$ Clinical Medical Department, Faculty of Medicine and \\ Pharmacy,University "Dunărea de Jos", Galați, România \\ ${ }^{3}$ Department of Dental Medicine, Faculty of Medicine and Pharmacy, \\ "Dunărea de Jos" University of Galați, Galați, România \\ ${ }^{4}$ Medical Assistance Service of the Municipality of Galați, Galați, România
}

\section{moroianu.g.marius@gmail.com}

ABSTRACT - Marijuana is the most widely used psychoactive substance after coffee and it is used for both medical and recreational purposes. It has been known since ancient times and it seems to have been part of the mixture that was put in the pipe of "peace" by Native Americans. Marijuana is psychically addictive, but in its case, there is no physical addiction as in the case of high-risk drugs (heroin) and over $70 \%$ of consumers do not recognize marijuana addiction. This substance can induce an acute psychotic episode and the onset of schizophrenia. Usually, the patient's family is the one who asks for help in their case. We chose to present the clinical case of a patient, initially, marijuana addicted, who, after stopping it, developed an internet gaming disorder addiction. The digital environment is constantly evolving, growing exponentially at a considerable rate and online networks mean creating connections between people, minds and memories, regardless of their location in space and time. Many of us have different passions but there are also people who take these passions to the extreme as is the case with our patient who has developed an addiction to video games. Thus, we can conclude that one addiction can be replaced by another one in a very short time.

KEYW ORDS - marijuana, video game addiction, internet gaming disorder, depression, anxiety .

\section{INTRODUCTION}

Since 2013, the American Psychiatric Association has decided that addictions should be divided into 2 subgroups: substance addictions and nonsubstance addictions such as gambling and excessive internet use, exercise, work or excessive sex. Even if those in the second category are not finalized as a diagnosis of mental disorder, there are many similarities between the two categories such as: in both can be found withdrawal symptoms when not playing/ consuming the addictive substance, tolerance, unsuc- cessful attempts to reduce or stop playing/ using the substance, gives up other activities to play/ use the addictive substance, continues playing/ using despite problems caused by it (American Psychiatric Association, 2013; Petry et al., 2015).

Psychiatric symptoms that are associated with internet gaming disorder are depression, anxiety, social isolation and, also, there are studies that agree that persons with internet and gaming addiction had higher rates of depressive symptoms than those without any addictions (Van Rooij et al., 2010; Mentzoni et al., 2011; Van Rooij et al., 2014).

The patients that are socially isolated and have poor interpersonal skills (Cășvean, 2021; Clero, 2018; Pavlovici, 2021; Sandu \& Nistor, 2020) are mostly attracted to games that particularly allow them to develop easy online relationships and take on a multitude of new personalities (Radulescu et al., 2020). Low sociability and social competence seem to be correlated with gaming problems (Festl et al., 2013; Lemmens et al., 2009; Rehbein et al., 2010).

\section{CASE DESCRIPTION}

We will present the case of the patient D.A., a 23 years old male who was brought to the hospital, by his family, for: apathy, increased anxiety, insomnia, delusional follow-up ideas. It should be mentioned that in the patient's family there are no chronic or mental illnesses, and from his personal history we remember: appendicectomy at 15 years, psychiatric history (first hospitalization 2 months ago with acute psychotic episode) and there is also no history of chronic, infectious or mental illness. The patient lived alone in the city, have been studying informatics and had a stable job at a multinational (tester position for games), but without a stable romantic relationship being addicted to marijuana since he was 19 years old, an addiction that he did not ever take it seriously.

History of the disease: a 23-year-old patient, having a psychiatric hospitalization so far, who lives in the city, is examined in emergency room for apathy, increased anxiety, insomnia and delusional follow-up ideas, symptoms that started about 3 months ago and exacerbated in the last month prior to the consultation due to therapeutic abandonment and resumption of marijuana use.

From a clinical and paraclinical point of view, there are no pathological changes. 
Examination of mental state at the time of examination: the patient has a slightly sad mood, he seems apathetic, anxious, with street clothes and maintained hygiene. From a cognitive point of view, bradypsychia and bradylalia are noticeable and the ideas of grandeur predominates "I have an IQ of 160, you don't even know who you're talking to". At the time of examination, he denies suicidal thoughts, but states that "I thought what I would be like to be dead and have an astral projection." He also presented mixed insomnia, decreased appetite, decreased useful yield (currently sick leave), insight on absent disease "I'm not sick, I just have a bat time".

Psychological examination: after applying the semi-structured interview (SCID), the psychological examination reveals borderline personality disorder (15/15 elements) and antisocial personality disorder (10/15 elements) with IQ=109/180-200. The structure obtained, for the changes noticed after completing the SCID, summarizes a criminal, aggressive, impulsive and irresponsible behavior.

Positive diagnosis: acute psychotic episode based on lack of insight, presence of delusional ideas, disorganized thinking, behavioral disorders, marijuana use and therapeutic abandonment.

The first treatment instituted in the hospital was suspended by the patient without any medical indication ("I didn't need that treatment, they made me sick and I can't stay in this state of mind").

The administration of the treatment is resumed with the patient's consent "I take it, but with one condition, don't make me a vegetable because I won't take it again".

He was administered: Trazodonum $150 \mathrm{mg}$, Risperidonum solution $4 \mathrm{ml} /$ day (previously had $8 \mathrm{ml} /$ day), Tryhexiphenidilum $2 \mathrm{mg}$ and Modafinilum $100 \mathrm{mg}$.

The patient returns to the consultation in the first 3 months, every 2 weeks (consultations are scheduled in advance by his mother). The evolution is quickly favorable, marijuana use has stopped ("these drugs you give me make me feel like when I take marijuana and I'm not flattened"), has a difficult social reintegration, but returns to work (game tester) for the second month of treatment. 7 months after the first consultation, he returns urgently for work addiction, in fact it is about internet gaming and video addiction, gaming addiction replacing marijuana addiction. With the "internet and gaming addiction" the nictemeral rhythm has changed, it shows weight loss ("I work hard, I'm a performer, I don't have time for your meals") although there is a well-specified work schedule. The idea of grandeur is present and exacerbated ("I create, I open hearts and minds"). He gives up without the doctor's advice to drug treatment and refuses hospitalization and help, but promises to continue at home with Risperidonum $4 \mathrm{ml} /$ day, while also trying psychotherapy.

The prognosis and the evolution of the case are unfavorable, the patient being male with personality disorder, vicious type, having insight of the disease absent and therapeutic abandonment.

\section{DISCUSSION}

There is little data about internet gaming disorder or video gaming and substance use (Sussman et al., 2011). There are some studies that found no differences between those with internet gaming disorder and those without this pathology in terms of alcohol use, but there might be a strong connection between the first and the use of illicit drugs such as marijuana (Luca et al., 2020a; Porter et al., 2010,), fact also demonstrated in our presentation. There are studies that emphasize the connection between internet gaming disorder and cigarettes smoking, drinking and marijuana or illicit drugs' usage (Desai et al., 2010; Luca et al., 2020b; Van Rooij et al., 2014;) but there were also some researches that could not found any association between alcohol and tobacco use and gaming but there were stated a relationship between marijuana addiction and gaming addiction (Walther et al., 2012).

Our case report is to evaluate the associations between personality characteristics such as impulsivity and lower social competence, marijuana use and internet game playing and it resulted that all of these are connected by impulsivity as a common feature. Impulsivity is a core aspect of substance use disorders, and it may play a role in the development and/or maintenance of the internet gaming disorder as well (Gentile et al., 2011; Petry et al., 2015). Also, in our case, Treatment acceptance and subsequently treatment adherence may depend of our patient's response while doing psychotherapy. It is considered that psychotherapy and the use of motivational interview can change a patient's perspective about medical treatment, accepting it easier and for a longer period of time (Curis et al., 2018; Valcea et al, 2016).

Maintenance of internet gaming disorder was associated with having lower grades in school, reporting poorer relationships with parents, and developing worsening of depression, anxiety, and social phobia symptoms over time, facts confirmed in our presentation (Gentile et al., 2011).

The case presented by the present can be considered a starting point for the evaluation, diagnosis and treatment of patients who initially have substance addiction, and after a period of time, do not return to their consumption, but develop non-substance addictions as on the present case, video game addiction that 
can also generate internet gaming addiction as well as vice versa thus being able to conclude that is a vicious circle: marijuana usage (substance addiction) - lower social competence (poor relationship with family and friends) - internet gaming and video disorder.

\section{Conflict of interest disclosure}

There are no known conflicts of interest in the publication of this article. The manuscript was read and approved by all authors.

\section{Compliance with ethical standards}

Any aspect of the work covered in this manuscript has been conducted with the ethical approval of all relevant bodies and that such approvals are acknowledged within the manuscript.

\section{Author contributions}

All authors have contributed equally to this paper.

This research was presented at $5^{\text {th }}$ European

$$
\text { Acknowledgment }
$$

Conference of Psychiatry and Mental Health "Galatia" 2021.

\section{REFERENCES}

1. American Psychiatric Association. (2013). Diagnostic and statistical manual of mental disorders ( 5 th ed.) DSM-5TM.

2. Cășvean, T. M., Hodorogea, V., \& Cășvean, I. E. (2021). The experience created by the social and cultural context constructed by video games: A digitization of life and death. Journal for Social Media Inquiry, 3(1), 19-31. https://doi.org/10.18662/ jsmi $/ 3.1 / 14$

3. Clero, J. P.(2018). Medicine, robot and intimacy. Journal for Ethics in Social Studies, 2(1), 1-21. https://doi.org/10.18662/jess/06

4. Curis, C., Ciubara, A. B, Nechita, A., Nechita, L., Kantor, C., Moroianu, L.A. (2018). The role of the motivational interview in treatment acceptance. Case report. Medical Surgical Journal- Revista Medico-chirurgicala, 122(2), 375-380. https:// www.revmedchir.ro/index.php/revmedchir/article/ view/1172/1021

5. Desai, R. A., Krishnan-Sarin, S., Cavallo, D., \& Potenza, M. N. (2010). Video-gaming among high school students: health correlates, gender differences, and problematic gaming. Pediatrics, 126(6), e1414-24. https://doi.org/10.1542/peds.2009-2706

6. Festl, R., Scharkow, M., \& Quandt, T. (2013). Problematic computer game use among adolescents, younger and older adults. Addiction, 108(3), 592-599. https://doi.org/10.1111/add.12016

7. Gentile, D. A., Choo, H., Liau, A., Sim, T., Li, D., Fung, D., Khoo, A. (2011). Pathological video game use among youths: a two-year longitudinal study. Pediatrics, 127(2), 319-329. https://doi.org/10.1542/ peds.2010-1353

8. Lemmens, J. S, Valkenburg, P., \& PeTER, J. (2009). Development and validation of a game addiction scale for adolescents. Media Psychology, 12(1), 77-95. http://dx.doi. org/10.1080/15213260802669458

9. Luca, L., Burlea, S. L., Chirosca, A.-C., Marin, I. M., Ciubara, A. B., \& Ciubara, A. (2020). The FOMO Syndrome and the Perception of Personal Needs in Contemporary Society. BRAIN. Broad Research in Artificial Intelligence and Neuroscience, 11(1Sup1), 38-46. https://doi.org/10.18662/ brain/11.1Sup1/27

10. Luca, L., Ciubara, A. B., Fulga, I., Burlea, $S$. L., Terpan, M., \& Ciubara, A.M. (2020b). Social Implications for Psychiatric Pathology of Depressive and Anxiety Disorders, Alcohol Addiction and Psychotic Disorders during the COVID-19 Pandemic in Romania. Analysis of two Relevant Psychiatry Hospitals. Revista de cercetare si interventie sociala, 69, 261-272. https://doi.org/10.33788/rcis.69.16

11. Mentzoni, R. A., Brunborg, G. S., Molde, H., Myrseth, H., Skouverøe, K. J., Hetland, J., Pallesen, S. (2011). Problematic video game use: estimated prevalence and associations with mental and physical health. Cyberpsychology, Behavior, and Social Networking, 14(10), 591-596. https://doi. org/10.1089/cyber.2010.0260

12. Pavlovici, B. (2021). A firefighter saving virtual addictions. BRAIN. Broad Research in Artificial Intelligence and Neuroscience, 12(2), 358-363. https:// doi.org/10.18662/brain/12.2/213

13. Petry N. M., Rehbein F., Ko C. H., O’Brien, C. (2015). Internet Gaming Disorder in DSM- 5, Current Psychiatry Reports, 17(9), 72. https://doi. org/10.1007/s11920-015-0610-0

14. Porter, G., Starcevic, V., Berle D., \& FeneCH, P. (2010). Recognizing problem video game use. Australian \& New Zealand Journal of Psychiatry, 44(2), 120-128. https://doi. org/10.3109/00048670903279812

15. Radulescu, I. D., Ciubara, A. B., Moraru, C., Burlea, S. L., \& Ciubară, A. (2020). Evaluating the Impact of Dissociation in Psychiatric Disorders. BRAIN. Broad Research in Artificial Intelligence and Neuroscience, 11(3Sup1), 163-174. https://doi. org/10.18662/brain/11.3Supl/132

16. Rehbein, F., Kleimann, M., \& Mössle, T. (2010). Prevalence and risk factors of video game dependency in adolescence: results of a German nationwide survey. Cyberpsychology, Behavior, and Social Networking, 13(3), 269-277. https://doi.org/10.1089/cyber.2009.0227

17. SAndu, A., \& Nistor, P. (2020). Digital dementia. Eastern-European Journal of Medical Humanities and Bioethics, 4(1), 1-10. https://doi.org/10.18662/ eejmhb/4.1/22 
18. Sussman, S., Lisha, N., \& Griffiths, M. D. (2011). Prevalence of the addictions: a problem of the majority or the minority? Eval Health Prof., 34(1), 53-56. https://dx.doi. org/10.1177\%2F0163278710380124

19. Valcea, L., Bulgaru-Iliescu, D., Burlea, S. L., Ciubara, A. (2016). Patient's rights and communication in the hospital accreditation process. Revista de Cercetare si Interventie Sociala, 55, 260-270. https:// www.rcis.ro/images/documente/rcis55_17.pdf

20. Van Rooij, A. J., Schoenmakers, T. M., VerMUlST, A. A. , VAN DEN Eijnden, R. J., VAN de Mheen, D. (2010). Online video game addiction: identification of addicted adolescent gamers. Addiction, 106(1), 205-212. https://doi.org/10.1111/ j.1360-0443.2010.03104.x
21. Van RooiJ, A. J., Kuss, D. J., Griffiths, M. D., Shorter, G. W., SChoenmakers, M. T., VAN DE Mheen, D. (2014). The (co-)occurrence of problematic video gaming, substance use, and psychosocial problems in adolescents. Journal of Behavioral Addictions, 3(3), 157-165. https://dx.doi. org/10.1556\%2FJBA.3.2014.013

22. Walther, B., Morgenstern, M., \& HanewINKEL, R. (2012). Co-occurrence of addictive behaviours: personality factors related to substance use, gambling and computer gaming. European Addiction Research, 18(4), 167-174. https://doi. org/10.1159/000335662 